Mots. Les langages du politique

70 | 2002

La politique en chansons

\title{
Frédériki Tabaki-Iona, Chants de liberté en 1848
}

\section{Maurice Tournier}

\section{OpenEdition}

Journals

Édition électronique

URL : https://journals.openedition.org/mots/9813

DOI : $10.4000 /$ mots. 9813

ISSN : 1960-6001

\section{Éditeur}

ENS Éditions

\section{Édition imprimée}

Date de publication : 1 novembre 2002

Pagination : 144-147

ISBN : 2-84788-016-X

ISSN : 0243-6450

\section{Référence électronique}

Maurice Tournier, «Frédériki Tabaki-Iona, Chants de liberté en 1848 », Mots. Les langages du politique [En ligne], 70 | 2002, mis en ligne le 07 mai 2008, consulté le 23 avril 2022. URL : http:// journals.openedition.org/mots/9813; DOI : https://doi.org/10.4000/mots.9813 
Frédériki TABAKI-IONA, Chants de liberté en 1848, Budapest, Turin, Paris, L'Harmattan, 2001, 276 p.

Dans le prolongement de ses recherches sur le mouvement «philhellénique $»{ }^{1}$, où les plus grands poètes français ont pris part verbalement aux luttes pour l'indépendance de la Grèce, et passant de la Restauration à la Monarchie de Juillet, F. Tabaki aboutit à la riche production chansonnière et poétique de 1848 . De ce foisonnement qui a précédé et accompagné la révolution et la seconde République, elle a su ordonner les thèmes essentiels en ressortant du passé des archives une remarquable sélection commentée de couplets et refrains, célèbres à l'époque, oubliés depuis. "Poésie forte et vraie », disait Baudelaire des chansons de Pierre Dupont.

On suit d'abord avec les chansonniers les grands moments de l'Histoire. À la " chute de la Royauté » apparaissent, comme dans un théâtre de foire, des silhouettes comiques, hautes en couleur, de Louis-Philippe et de son «valet» Guizot lors de leur « décampement", mêlées à une métaphorisation héroïque de l'effondrement de la Monarchie sous les coups du Peuple :

Tremblez Césars, potentats, race immonde! [...]

[...] Volons au but! L'ouragant populaire

Balaye un roi qui barrait les chemins (Festeau).

C'est l'époque enthousiaste où le Peuple devient Roi à son tour :

Le chant du Peuple est la charte du monde.

Foulons aux pieds ce qui reste des rois (Bonabot).

" Chère Liberté », « douce Fraternité » et « sainte République » sont les cris de ralliement. S'ouvre ensuite une « Ère nouvelle », caractérisée par la foi dans le Progrès ou dans la «République Démocratique et Sociale » (qui va devenir "La Sociale »), par la célébration utopiste (de Félicien David à Vinçard) et - en plus vindicatif - par la revendication des Droits du Travail et des Droits de la Femme. Les Marseillaises et les Chants du départ se multiplient à leur propos : La Chanson des Travailleurs, Le Chant du Travail ou la Marseillaise pacifique, La Française, La Marseillaise européenne, La Marseillaise de l'époque, La Mar-

1. F Tabaki-Iona, Poésie philhellénique et périodiques de la Restauration, Athènes, Société des Archives helléniques, littéraires et historiques, 1993. 
seillaise des femmes, le Chant du départ des Vésuviennes, etc. A en croire certaines chansons, l'espérance attendait tout d'une fraternité universelle :
Allons, enfants de la Patrie,
De nous unir, voici le jour!
De toutes parts le ciel nous crie :
Fondez le règne de l'amour! (Caldelar).

Juin 48 : désillusions, chômage, révolte, répression. Ce sont les frustrations ouvrières puis le massacre des «insurgés" sur les barricades qu'évoque l'excellent chapitre sur " La guerre des classes ». De grands chansonniers ouvriers comme Charles Gilles expriment en vers hugoliens cette rancœur devant la trahison des attentes populaires ou l'espoir déçu de la paix sociale :

Tu dors, Brutus, et Rome est dans les fers

De la République bourgeoise (Gilles).

Sur les tombeaux où s'endorment nos frères

Allons poser le rameau de la paix (Festeau).

Ni la mort de l'archevêque, ni les pétitions contre la «transportation », ni l'évocation des "martyrs» n'y pourront rien. "Paris se voile de ténèbres » (Loynel). Il ne reste plus qu'à prêcher la concorde et à constater, effaré ou applaudisseur, la «marche vers la présidence » du « petit neveu du grand homme ». On prévient, sur l'air de Mimy Pinson : «République, prends garde à toi!» (Mercier). Et c'est peut-être Gérard de Nerval qui a publié dans la Revue comique le refrain anonyme :

Des prétendants, l'heure est passée.

Bons citoyens, chassez-le donc!

À ce voyage chansonné à travers les quatre mois révolutionnaires, F. Tabaki a fort habilement joint des sujets d'époque. On voit ainsi, au fil des évènements, apparaitre non seulement saint-simoniens, fouriéristes, cabétiens, " rouges » blanquistes, « communistes » (c'est-à-dire communautaires) et socialistes de toutes tendances, accompagnés de leurs féministes, mais aussi des thèmes majeurs, caractéristiques de l'esprit quarante-huitard. Le sentiment religieux y revêt la plus grande importance, chez les ouvriers comme chez les utopistes (Fourier, Cabet, et surtout Buchez et L'Atelier, dans la ligne de Lamennais). Tenus à part du clergé conservateur, le "Christ rouge » et le Peuple s'identifient. Baudelaire et Champfleury écrivent dans leur journal Le Salut public : « JésusChrist est le fondateur de toutes les républiques modernes; quiconque en 
doute n'a pas lu l'Evangile ». Eugène Pottier célèbre ainsi la plantation des arbres de la liberté :

Un premier arbre aux forces vives

Fut pris au jardin des olives.

Ce qui donne en occitan :

Vive la Républiqua!

Gloire à Diu qui nous l'a baillie!

Bien entendu des thèmes inverses se chantent en contrepoint. Deux célèbres chansons heurtent leurs refrains à propos de Cabet : en réponse à la chanson anonyme répandue dans tout Paris en avril,

Le communisme est le rêve des fous $[\ldots]$

Le fainéant veut le partage,

le poète ouvrier Lachambaudie diffuse par affiches son refrain « $\mathrm{Ne}$ criez plus : À bas les communistes! ». Il en est de même pour la religion. On dénonce Jésuites et couvents pour ne vivre que de « rapines » :

Détruisons l'hydre jésuitique... (Koueman)

C'est un fléau que cette monacaille... (Sain).

D'où l'idée de plus en plus commune d'opposer Jésus et l'Église :

Aux maximes de l'Évangile

Que le prêtre soit plus docile (Randon).

Une intéressante réflexion sur le temps clôt l'ouvrage et pratique comme une couture entre les évènements et les thèmes. Le futur (« Nous marcherons », « Nous serons les maitres »...) domine avec les espoirs de liberté entrevus, et que d'optatifs, d'exclamatifs et d'impératifs dressent des verbes de mouvement!

Venez, enfants de Cracovie!

Un jour de gloire est arrivé (Marcel).

Allons debout, France! Plus d'inertie! [...]

Peuple, debout! Paris reprends les armes! (Drappier).

En avant, les Voraces!

Vive la liberté! (Randon).

Multiplication des images cataclysmiques aussi. On attend le Grand Jour de l'égalité... "L'heure est venue. Tyrans, tremblez d'effroi » (Leroy). Le passé, lui, est révolu : ancien monde à rayer du souvenir ou 
gloires révolutionnaires et napoléoniennes en proie à une " rétrospection sélective depuis 1789 », ainsi que le montre F. Tabaki.Il faudrait tout citer, tant cet ouvrage s'avère riche d'aperçus judicieux et d'attestations excellemment choisies; il vaut mieux le lire. Toutes les vibrations d'une époque y sont à redécouvrir.

Maurice Tournier

Michel PASTOUREAU, Bleu. Histoire d'une couleur, Paris, Le Seuil, 2000, 216 p.

Après un Dictionnaire des couleurs de notre temps (Bonneton, 1992), et une exploration des Rayures (Le Seuil, 1995), M. Pastoureau nous donne une passionnante synthèse sur l'histoire sociale des couleurs en Occident. Sans jamais perdre le fil bleu conducteur, il nous fait passer des conjonctures courtes aux très longues durées et met à mal les explications univoques (une cause matérielle produisant une conséquence idéologique). Il fait servir les disciplines les plus diverses (histoire religieuse, politique, littéraire, artistique, mais aussi économie et technique des teintures, héraldique ou sociologie), à l'illustration de son propos fondamental : «C'est la société qui fait la couleur [...] pas l'artiste ou le savant; encore moins l'appareil biologique de l'être humain ou le spectacle de la nature » (p. 9). Foin donc des causalités simplettes, des « prétendues vérités universelles ou archétypales », et place à «l'histoire mouvante des savoirs $»$.

En feuilletant le livre, on appréciera d'emblée la beauté des illustrations, toujours précisément référencées. Puis, au fil de quatre chapitres diachroniques, on suivra sur la longue durée, de l'Antiquité à nos jours, les mutations de la couleur. Ou, plus exactement, des systèmes sociosymboliques qu'elle accompagne, concrétise et organise. La couleur, ça sert d'abord à classer, c'est-à-dire à distinguer et opposer des objets, des fonctions, des personnes. Ce principe structuraliste de base est valable pour tout champ d'étude; encore faut-il arriver à dégager, de la prolifération du réel documentaire, un système simple, quelques axes et valeurs, un « ordre ». Quel est donc celui des couleurs en Occident?

- De l'Antiquité au $12^{\mathrm{e}}$ siècle, le système de base est tripolaire : le blanc s'oppose au noir et au rouge, qui est « la » couleur par excellence. Ce très ancien système chromatique sert, par exemple, au regroupement trifonctionnel des classes dans la Rome antique, et on le retrouve au 